Article

\title{
Antifungal Activity of Squid Pen Chitosan Nanoparticles against Three Fungal Pathogens in Various Citrus Fruits In Vitro and In Vivo
}

\author{
Hoang Ngoc Cuong ${ }^{1, *}$, Nguyen Cong Minh ${ }^{2}$, Nguyen Van Hoa ${ }^{3, *(\mathbb{D}}$, Dang Ha Giang ${ }^{4}$, Nguyen Van Hieu 4 \\ and Pham Viet Nam ${ }^{5}$
}

check for

updates

Citation: Cuong, H.N.; Minh, N.C.; Hoa, N.V.; Giang, D.H.; Hieu, N.V.; Nam, P.V. Antifungal Activity of Squid Pen Chitosan Nanoparticles against Three Fungal Pathogens in Various Citrus Fruits In Vitro and In Vivo. Coatings 2022, 12, 235. https:// doi.org/10.3390/coatings12020235

Academic Editor: Catalina Natalia Cheaburu-Yilmaz

Received: 28 December 2021

Accepted: 9 February 2022

Published: 11 February 2022

Publisher's Note: MDPI stays neutral with regard to jurisdictional claims in published maps and institutional affiliations.

Copyright: (C) 2022 by the authors. Licensee MDPI, Basel, Switzerland. This article is an open access article distributed under the terms and conditions of the Creative Commons Attribution (CC BY) license (https:// creativecommons.org/licenses/by/ $4.0 /)$
1 Faculty of Biotechnology, Binh Duong University, Thu Dau Mot 590000, Vietnam

2 Institute for Biotechnology and Environment, Nha Trang University, Nha Trang 650000, Vietnam; minhnc@ntu.edu.vn

3 Faculty of Food Technology, Nha Trang University, Nha Trang 650000, Vietnam

4 Department of Science and Technology, Dong Xoai 830000, Vietnam; danghagiang.skhcn@binhphuoc.gov.vn (D.H.G.); nguyenvanhieu.skhcn@binhphuoc.gov.vn (N.V.H.)

5 Faculty of Fishery, Ho Chi Minh City University of Food Industry, Ho Chi Minh City 700000, Vietnam; nampv.fisheries@gmail.com

* Correspondence: hncuong@bdu.edu.vn (H.N.C.); hoanv@ntu.edu.vn (N.V.H.)

Abstract: Fungal infections have been considered a primary cause of the postharvest losses of citrus fruits. Therefore, it is necessary to find low-cost and high antifungal activity materials for preventing the decay of citrus fruits after harvest. In this study, squid chitosan nanoparticles (SCNs) were prepared from squid pen chitosan and used as a biofungicide against three citrus fungal pathogens in both in vitro and in vivo evaluations. The prepared SCNs had a mean size of ca. $56 \mathrm{~nm}$ and a high zeta potential of $+98.7 \mathrm{eV}$ with a narrow size distribution. At a range of 50-250 ppm, the SCN concentration of 200 ppm exhibited the highest activity in totally inhibiting the growth of Lasiodiplodia pseudotheobromae, Alternaria alternate, and Penicillium digitatum in in vitro tests where these fungi were isolated from symptomatic fruits and identified. Furthermore, after 12 days of incubation at $30 \pm 0.2{ }^{\circ} \mathrm{C}$ and high relative humidity in in vivo studies, the infection area of the sample treated at 250 ppm completely suppressed fruit disease symptoms. The results demonstrate that prepared SCNs efficiently control postharvest citrus fruit diseases. These findings recommend applying SCNs as a potential candidate for citrus fruit storage.

Keywords: squid pens; chitosan nanoparticles; antifungal activity; citrus fruits; fungal pathogens

\section{Introduction}

Citrus is an important fruit with a world production estimated at over 100 million tons per year [1]. In Vietnam, citrus is widely grown as a high economic fruit in the Northern and Southern provinces. However, citrus fruits have a low $\mathrm{pH}$ value, high moisture content, and many nutrients making them very susceptible to attack by pathogenic fungi [2]. So, the postharvest losses usually are high during the storage stage, and the loss rate is about $15-35 \%$ of the total output, which causes severe economic losses after harvest. It was reported that Lasiodiplodia pseudotheobromae, Alternaria alternate, and Penicillium digitatum were the main disease problems with blue mold, green mold, and watery rot and unexpected flavor during postharvest storage [3,4]. So far, an effective fungicide has mainly managed these fungi [5], but its intensive use may cause resistant isolates to develop and pose several risks for human and environmental health. Therefore, it is necessary to create safe alternatives for controlling postharvest rots [6].

Chitosan is a biodegradable, nontoxic, and abundant polymer $[7,8]$. Furthermore, it is well-known to have a broad spectrum of antimicrobial activities [9]. Chitosan has been reported to have high fungal activity against many phytopathogenic fungi [10,11], which 
cause several fungal plant diseases [12-14]. Recently, chitosan-based nanoparticles have been widely studied for various applications because of their small size, good biocompatibility and degradability, high permeability, high antimicrobial property, low cost, and facile preparation [15-19]. Practically, chitosan nanoparticles have affected and prevented the growth of fungi on citrus fruits, such as P. steckii and A. oryzae [17], C. albicans [20,21], A. fumigatus [22], and Xanthomonas oryzae pv. Oryzae [23]. It has been indicated that the antifungal activity of chitosan nanoparticles depended on its concentration, the molecular weight of base initial chitosan or functional groups added to the chitosan, and the target pathogen. However, these published works have mainly focused on the antifungal activities of chitosan nanoparticles prepared from shrimp chitosan [24-26]. So far, no investigations on the antifungal activity of squid chitosan nanoparticles against the fungal pathogens in citrus fruits have been reported.

Based on these above considerations, the present study aims to determine the antifungal activity of squid chitosan nanoparticles against Lasiodiplodia pseudotheobromae, Alternaria alternate, and Penicillium digitatum caused by the decay of postharvest citrus fruits; the fungi were isolated from symptomatic fruits and identified. The antifungal tests were firstly performed under in vitro conditions. In addition, the antifungal activity of SCNs was evaluated on the development of three fungi in postharvest citrus fruits under in vivo conditions to expand the potential application of SCNs.

\section{Materials and Methods}

\subsection{Preparation of SCNs}

Sodium tripolyphosphate (TPP, $>99 \%$, Aldrich) and acetic acid $\left(\mathrm{CH}_{3} \mathrm{COOH}, 99.6 \%\right.$, Merck) were used as received. Chitosan ( $\mathrm{M}_{\mathrm{W}}$ of ca. $20 \mathrm{kDa}$, deacetylated degree of ca. $92 \%$ ) was prepared in the laboratory [27]. SCNs were prepared from squid chitosan by the ionic gelation method based on our previous report [28]. Typically, $20 \mathrm{~mL}$ of TPP solution $(0.05 \mathrm{wt} . \%)$ was added dropwise to $100 \mathrm{~mL}$ of chitosan solution $(0.05 \mathrm{wt} . \%$ in $1.0 \%(v / v)$ acetic acid) under stirring at $1500 \mathrm{rpm}$ and room temperature. After stirring for $10 \mathrm{~min}$, CSNs were received by centrifugal, followed by washing with deionized water three times to remove free chitosan, TTP, and acetic acid. The CSN solutions were prepared by dispersing CSNs in DI water for characterization and antifungal tests.

The particle size and zeta potential were determined by a Nano Particle Analyzer SZ-100 (Horiba Scientific, Kyoto, Japan) at $25{ }^{\circ} \mathrm{C}$ and transmission electron microscopy (TEM, Philips, CM-120, Eindhoven, The Netherlands) at an acceleration voltage of $120 \mathrm{kV}$. The prepared chitosan particles had a mean size of about $56 \mathrm{~nm}$ and high zeta potential of $+98.7 \mathrm{eV}$ with a narrow size distribution, as shown in Figure 1.
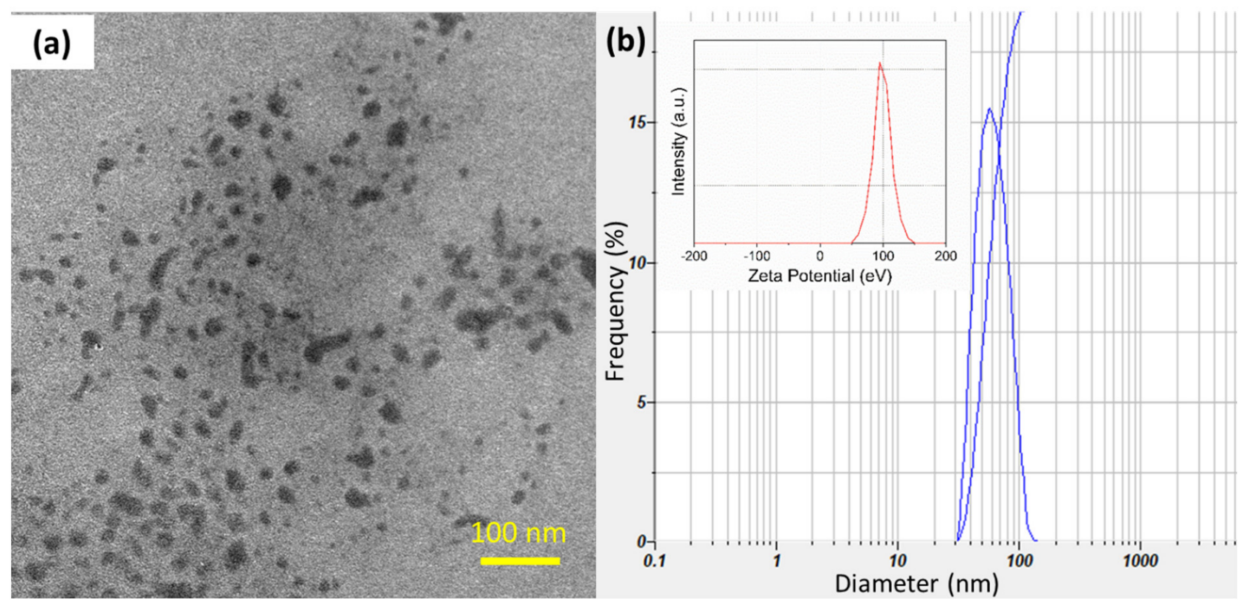

Figure 1. (a) TEM image and (b) the size distribution of prepared SCNs (Inset is the zeta potential of SCNs). The mean size is approximately $56 \mathrm{~nm}$. 


\subsection{Fruits Samples}

The three kinds of citrus fruits considered in this study include Citrus maxima, Citrus reticulata sinensis, and Citrus reticulata Blanco. The nondiseased and diseased citrus fruits were collected at Hon Quan and Binh Long districts, and Dong Xoai city in Binh Phuoc province, Vietnam. The fruits were packed in a cool box and then transferred to the laboratory.

\subsection{Pathogen Isolation and Identification}

Small pieces were cut from infected fruits by a sterile scalpel blade for isolating and identifying the pathogen of blue mold, green mold, and watery rot diseases. These pieces were dipped in a $10 \mathrm{wt} . \% \mathrm{NaClO}$ solution for $3 \mathrm{~min}$ and then washed with distilled water twice. The obtained samples were put in between two sterilized filter papers and dried. After that, the dried samples were placed on potato dextrose agar (PDA) containing a streptomycin sulfate (STS) at a ratio of STS/PDA 1:20 $(\mathrm{mg} / \mathrm{mL})$. The strain was grown at $30 \pm 0.2{ }^{\circ} \mathrm{C}$ for 12 days [29]. Afterward, obtained spores were suspended in PDA medium at the same conditions. Finally, the identification of three isolated fungi was based on morphological characteristics as well as physiological and biochemical properties by the Sanger method by ABI 3130/3500 equipment in the company Nam Khoa. For further investigations, the identified colonies were maintained at $5^{\circ} \mathrm{C}$ on a PDA medium.

\subsection{Antifungal Test}

In in vitro tests, various SCN solutions (50, 100, 150, 200, and $250 \mathrm{ppm}$ ) were mixed with the PDA. The obtained mixtures were sterilized at $121^{\circ} \mathrm{C}$ for $20 \mathrm{~min}$ and poured into the Petri dishes. Growing fungal mycelial plugs $(3 \mathrm{~mm} \times 3 \mathrm{~mm})$ were inoculated in the center of the dishes and incubated at $28 \pm 0.2{ }^{\circ} \mathrm{C}$ for 23 days [29]. The colony diameters of the fungi were measured after culturing for 1, 2, and 7 days. PDA without SCNs was tested as the negative control [30].

In in vivo tests, healthy citrus fruits (Citrus maxima; Citrus reticulata $\times$ sinensis, and Citrus reticulata Blanco) of uniform maturity and size were selected, washed with tap water, and dipped in a $10 \% \mathrm{NaClO}$ solution, rinsed with sterile water, and finally air dried under aseptic conditions. Then, each cleaned fruit was wounded at $3 \mathrm{~mm}$ deep and $5 \mathrm{~mm}$ wide by a sterile needle. Different concentrations of SCN solutions $(0,50,100,150,200$, and 250 ppm) were prepared and sprayed wholly through the cleaned fruit surface before adding $25 \mu \mathrm{L}$ of isolated fungal suspension $\left(10^{6} \mathrm{CFU}\right.$ spores $\left.\mathrm{ml}^{-1}\right)$ into the wound using a micropipette [12]. Treated fruits were placed under aseptic conditions for $3 \mathrm{~h}$. The treated fruits ( 5 fruit per treatment) were placed and sealed in plastic boxes containing a cup of water in order to maintain a high humidity. All treatments were incubated at $25 \pm 0.2{ }^{\circ} \mathrm{C}$ [31,32]. The fruits were visually observed for fungal symptoms, and the percent of decay was calculated through lesion diameters (mm) that were measured by a digital micrometer daily until the fruits were destroyed entirely [12]. All the fruit treatments were performed twice.

\subsection{Statistical Analysis}

All experiments were repeated three times. Minitab determined significant differences with a statistical variation among the samples at $p<0.05$.

\section{Results and Discussion}

\subsection{Isolation and Identification of the Fungi from Citrus Fruits}

Three fungi were isolated from diseased citrus fruits collected at four different locations in the Binh Phuoc province, Vietnam. Figures $2-4$ show that the plate and fruit were injected with a spore fungal suspension and incubated at $30^{\circ} \mathrm{C}$, and the $16 \mathrm{~s}$ rRNA gene sequences of these fungi were recorded identified. After 12 days of incubation, the colonies of Lasiodiplodia pseudotheobromae on the PDA medium were turquoise in color (Figure 2a), while the color of the Alternaria alternate and Penicillium digitatum colonies was dark brown (Figures 3a and 4a). All fungi developed very quickly after being injected with a spore fungal suspension, and the fruits were almost completely destroyed after 12 days, as 
shown in Figures $2 \mathrm{~b}, 3 \mathrm{~b}$ and $4 \mathrm{~b}$. In addition, the obtained fungal isolates were then identified by the Sanger sequencing method. These sequencing results were deposited on BLAST search and were indicated as being 100\%, 99.88\%, and 99.78\% homologous with Lasiodiplodia pseudotheobromae (Figure 2c), Alternaria alternate (Figure 3c), and Penicillium digitatum, respectively (Figure 4c). The morphological and culture characteristics of the obtained fungi are similar to those of previous reports [4-6,11,31,32]. These identified fungi were kept at $5{ }^{\circ} \mathrm{C}$ on a PDA medium and used for further in vitro and in vivo tests.

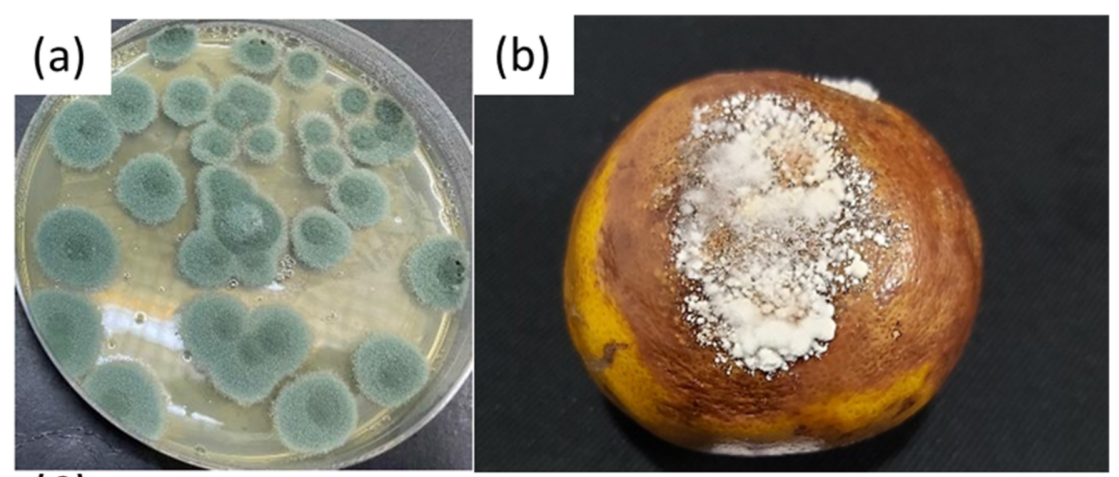

(C)

GTCGCTACTACCGATTGAATGGCTCAGTGAGGCCTTGGGATTGGCTTAGGAGGGTTGGCAACGACCCCCCAGAGCCGAAAACTTGGTCAAAC TCGGTCATTIAGAGGAAGTAAAAGTCGTAACAAGGTTTCCGTAGGTGAACCTGCGGAAGGATCATTACCGAGTGAGGGCCCTTTGGGTCCAA CCTCCCACCCGTGTTTATTTTACCTTGTTGCTTCGGCGGGCCCGCCTTTACTGGCCGCCGGGGGGCTTCACGCCCCCGGGCCCGCGCCCGCCGA AGACACCCTCGAACTCTGTCTGAAGATTGAAGTCTGAGTGAAAATATAAATTATTTAAAACTTTCAACAACGGATCTCTTGGTTCCGGCATCGA TGAAGAACGCAGCGAAATGCGATACGTAATGTGAATTGCAAATTCAGTGAATCATCGAGTCTTTGAACGCACATTGCGCCCCCTGGTATTCCG GGGGGCATGCCTGTCCGAGCGTCATTGCTGCCCTCAAGCCCGGCTTGTGTGTTGGGCCCCGTCCTCCGATTCCGGGGGACGGGCCCGAAAGG CAGCGGCGGCACCGCGTCCGGTCCTCGAGCGTATGGGGCTTTGTCACCCGCTCCGTAGGCCCGGCCGGCGCTTGCCGATCAACCCAAATTTIT ATCCAGGTTGACCTCGGATCAGGTAGGGATACCCGCTGAACTTAAGCATATCAATAAGCGGAGGAAAAGAAACCAACAGGGATTGCCCCAGT AACGGCGAGTGAAGCGGCAAGAGCTCAAATTTGAAAGCTGGCTCCTTCGGGGTCCGCATTGTAATTTGCAGAGGATGCTTCGGGAGCGGTCC CCATCTAAGTGCCCTGGAACGGGACGTCATAGAGGGTGAGAATCCCGTATGGGATGGGGTGTCCGCGCCCGTGTGAAGCT

Figure 2. (a) Plate and (b) fruit were injected with a spore fungal suspension and incubated at $30{ }^{\circ} \mathrm{C}$ for 12 days; (c) 16s rRNA gene sequences of the Penicillium digitatum.
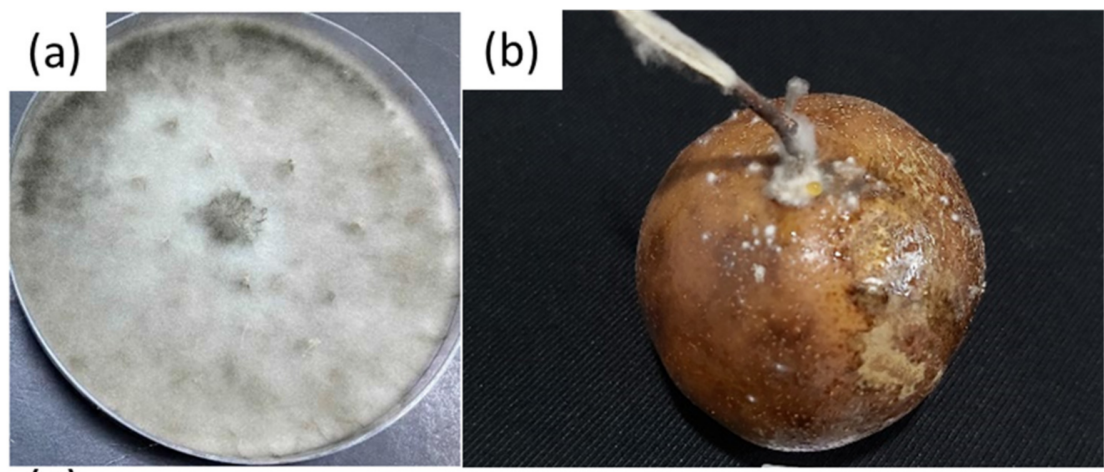

(c)

GTCGCTACTACCGATTGAATGGCTCAGTGAGGCCTTCGGACTGGCTCAGGGAGGTCGGCAACGACCACCCAGAGCCGGAAAGT CCGTCAAACTGCGTCATTTAGAGGAAGTAAAAGTCGTAACAAGGTTTCCGTAGGTGAACCTGCGGAAGGATCATTACCGAGTTT TCGGGCTTCGGCTCGACTCTCCCACCCTTTGTGAACGTACCTCTGTTGCTTTGGCGGCTCCGGCCGCCAAAGGACCTCCAAACTCC AGTCAGTAAACGCAGACGTCTGATAAACAAGTTAATAAACTAAAACTTTCAACAACGGATCTCTTGGTTCTGGCATCGATGAAGA ACGCAGCGAAATGCGATAAGTAATGTGAATTGCAGAATTCAGTGAATCATCGAATCTTTGAACGCACATTGCGCCCCTTGGTATT CCGGGGGGCATGCCTGTTCGAGCGTCATTACAACCCTCAAGCTCTGCTTGGAATTGGGCACCGTCCTCACTGCGGACGCGCCTCA AAGACCTCGGCGGTGGCTGTTCAGCCCTCAAGCGTAGTAGAATACACCTCGCTTTGGAGTGGTTGGCGTCGCCCGCCGGACGAA CCTTCTGAACTITTCTCAAGGTTGACCTCGGATCAGGTAGGGATACCCGCTGAACTTAAGCATATCAATAAGCGGAGGAAAAGA AACCAACAGGGATTGCCTTAGTAACGGCGAGTGAAGCGGCAACAGCTCAAATTTGAAAGCTGGCCCTTTTAGGGTCCGCGTTGT AATTTGTAGAGGATGATTCGGCGAGGGCTCCTGCCTAAGTCCCCTGGAACGGGGCGTCATAGAGGGTGAGAATCCCGTATGCG GTAGGTTGCCTTAGCCATGTGAATCTCCTTC

Figure 3. (a) Plate and (b) fruit were injected with a spore fungal suspension and incubated at $30{ }^{\circ} \mathrm{C}$ for 12 days; (c) 16s rRNA gene sequences of the Lasiodiplodia pseudotheobromae. 

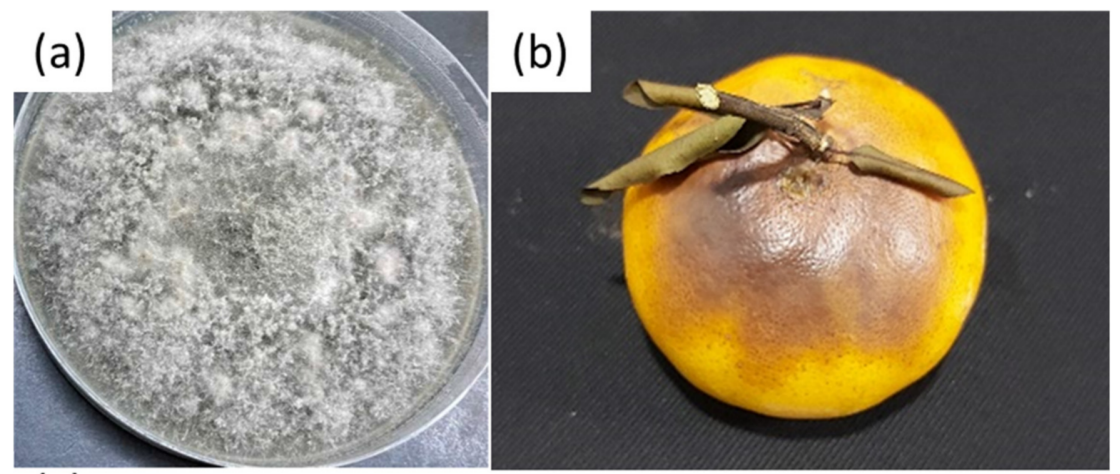

(c)

TGGCTCAGTGAGGCCTTCGGACTGGCTCGAGGAGGTTGGCAACGACCACCTCAAGCCGGAAAGTCGTCAAACTCGGTCATTTAGAGGAAGT AAAAGTCGTAACAAGGTCTCCGTAGGTGAACCTGCGGAGGGATCATTACACAAATATGAAGGCGGGCTGGAATCTCTCGGGGTTACAGCCTT GCTGAATTATTCACCCTTGTCTTITGCGTACTTCTTGTTCCTTGGTGGGTCGCCCACCACTAGGACAAACATAAACCTTITGTAATTGCAATCA GCGTCAGTAACAAATTAATAATTACAACTTTCAACAACGGATCTCTTGGTTCTGGCATCGATGAAGAACGCAGCGAAATGCGATAAGTAGTGT GAATTGCAGAATTCAGTGAATCATCGAATCTTTGAACGCACATTGCGCCCTTTGGTATTCCAAAGGGCATGCCTGTTCGAGCGTCATTTGTACC CTCAAGCTTTGCTTGGTGTGGGCGTCTTGTCTCTAGCTTTGCTGGAGACTCGCCTTAAAGTAATTGGCAGCCGGCCTACTGGTTTCGGAGCGC AGCACAAGTCGCACTCTCTATCAGCAAAGGTCTAGCATCCATTAAGCCTTIITTCAACTITTGACCTCGGATCAGGTAGGGATACCCGCTGAAC TIAGCATATCAATAAGCGGAGGAAAAGAAACCAACAGGGATTGCCCTAGTAACGGCGAGTGAAGCGGCAACAGCTCAAATTTGAAATCTGG CTCTITIAGAGTCCGAGTIGTAATTGCAGAGGGCGCTTTGGCTTTGGCAGCGGTCCAAGTTCCTTGGAACAGGACGTCACAGAGGGTGAGAA TCCCGTACGTGGTCGCTGGCTATTGCC

Figure 4. (a) Plate and (b) fruit were injected with a spore fungal suspension and incubated at $30{ }^{\circ} \mathrm{C}$ for 12 days; (c) 16s rRNA gene sequences of the Alternaria alternate.

\subsection{Pathogenicity Test}

In in vitro studies, the antifungal activity of SCNs against Lasiodiplodia pseudotheobromae (Figure 5), Alternaria alternate (Figure 6), and Penicillium digitatum (Figure 7) was examined on a PDA medium using SCN concentrations of 50, 100, 150, 200, and $250 \mathrm{ppm}$ and incubated at $28 \pm 0.2^{\circ} \mathrm{C}$. PDA without SCNs was tested as the negative control. Three 3 days after the inoculation, the colony of three fungi in the control samples was observed in white mold (Figures $5 \mathrm{~b}$ and $6 \mathrm{~b}$ ), and green mold (Figure $7 \mathrm{~b}$ ). In contrast, the SCNs significantly inhibited the growth and biomass of mycelium. The antifungal activity of SCNs may be explained by the fact that nanoparticles have a high surface area to volume ratio and unique chemical and physical properties, which increase their contact with microbes and the ability to permeate cells [33]. The potent inhibitory effect of chitosan on fungal growth was according to the damage of the plasma membrane of the mycelia and spores [32]. In addition, the higher the concentration used, the higher the antifungal activity observed in our tests. The concentration-dependent phenomenon was also reported in previous research $[17,33,34]$, which may be due to the strong interactions between chitosan's positive charges and the cell's negatively charged membranes [35]. As can be seen from the figures, SCNs wholly suppressed the mycelium linear growth, and biomass tested at a concentration of $200 \mathrm{ppm}$. No significant growth of the fungi was observed at $250 \mathrm{ppm}$ of SCNs.

In in vivo tests, three citrus fruits, including Citrus maxima; Citrus reticulata $\times$ sinensis, and Citrus reticulata were first injected with fungal suspensions of P. digitatum, L. pseudotheobromae, and A. alternate and then treated with SCNs at different concentrations. The samples were incubated at $25 \pm 0.2{ }^{\circ} \mathrm{C}$ for a week under high relative humidity. Concentrationdependent inhibition of the mycelial growth of three fungi by SCNs was observed, in agreement with the behavior in in vitro tests.

Table 1 and Figure 8 show that the disease reduction was enhanced by increasing the concentration up to $250 \mathrm{ppm}$. The SCNs treated at $200 \mathrm{ppm}$ significantly reduced the growth of rot symptoms of citrus maxima caused by P. digitatum, L. pseudotheobromae, and $A$. alternate. However, the SCNs displayed a higher antifungal activity against $L$. pseudotheobromae than those of $P$. digitatum and A. alternate. Practically, the SCNs highly reduced the mold infection and the lesion diameter to $15.6 \%$ and $2.1 \mathrm{~cm}$ (P. digitatum), 
$1.7 \mathrm{~cm}$ (L. pseudotheobromae), and $2.3 \mathrm{~cm}$ (A. alternate) after a week of incubation, respectively compared with the control of $100 \%$ and $15.0 \mathrm{~cm}$. Moreover, as can be seen in Figure 8 , the control fruits appeared blighted, and there were water-soaked dark brown areas up to the seventh day of incubation. Conversely, no blight and rot symptoms were observed on the treated fruits at $250 \mathrm{ppm}$ in all cases. These results are somewhat compatible with those found on antifungal tests in vitro.
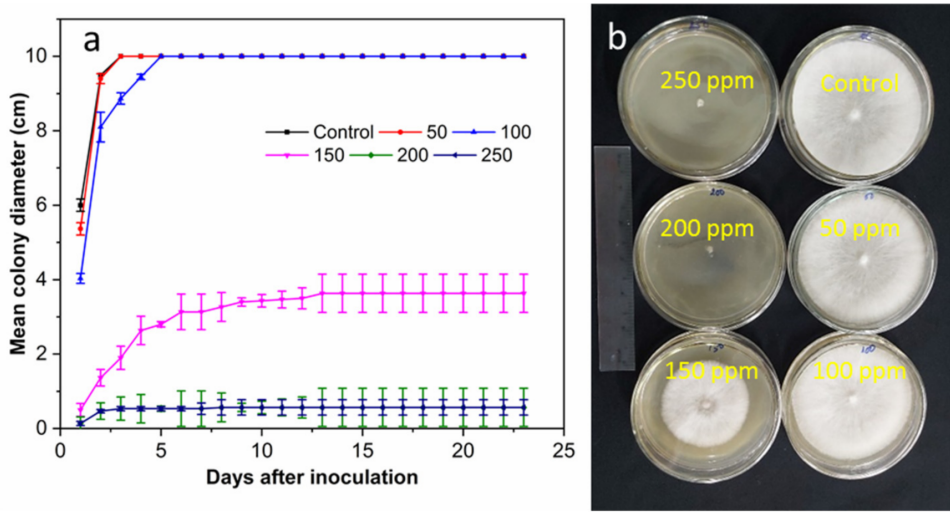

Figure 5. (a) The antifungal activity of SCNs at different concentrations against L. pseudotheobromae incubated at $28{ }^{\circ} \mathrm{C}$ for 23 days and (b) plates incubated for 3 days.
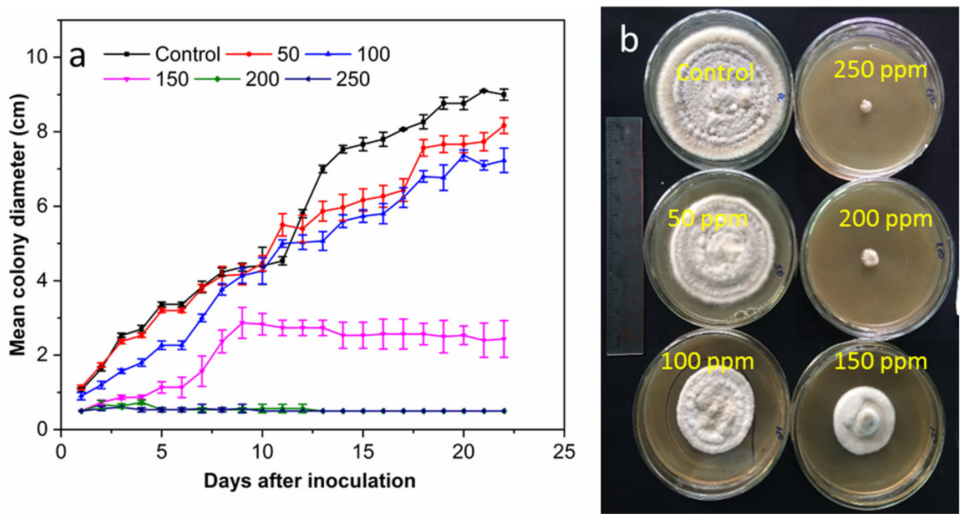

Figure 6. (a) The antifungal activity of SCNs at different concentrations against $A$. alternate incubated at $28{ }^{\circ} \mathrm{C}$ for 22 days and (b) plates incubated for 16 days.

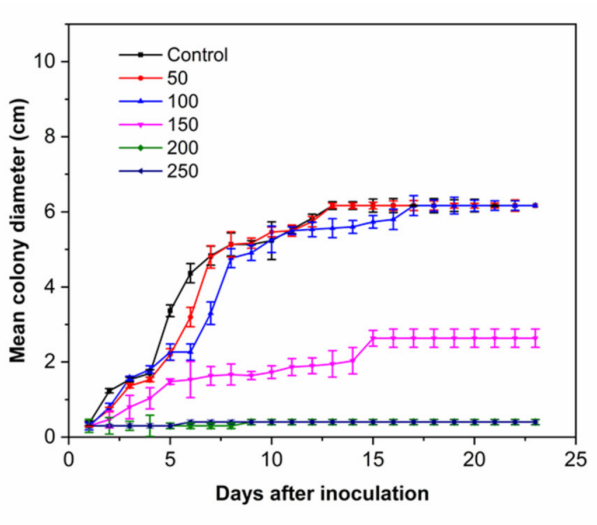

(a)

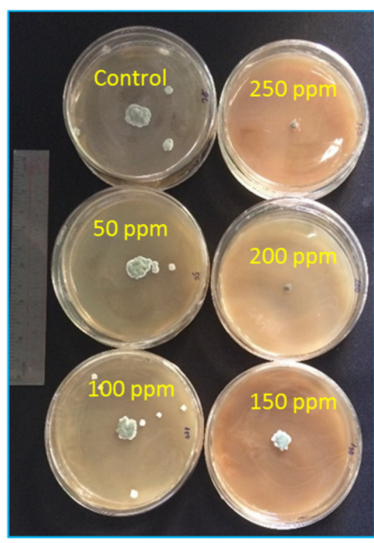

(b)

Figure 7. (a) The antifungal activity of SCNs at different concentrations against $P$. digitatum incubated at $28{ }^{\circ} \mathrm{C}$ for 23 days and (b) plates incubated for 7 days. 
Table 1. The antifungal activity of SCNs at different concentrations against three fungi on Citrus maxima.

\begin{tabular}{ccccc}
\hline \multirow{2}{*}{$\begin{array}{c}\text { SCNs } \\
(\mathbf{p p m})\end{array}$} & $\begin{array}{c}\text { Infection } \\
(\mathbf{\%})\end{array}$ & \multicolumn{3}{c}{ Mean Lesion Diameter $(\mathbf{c m})$} \\
\cline { 3 - 5 } & 100 & 15.0 & P. pseudotheobromae & A. alternate \\
\hline 0 & 100 & 15.0 & 15.0 & 15.0 \\
50 & 85.3 & 9.3 & 15.0 & 15.0 \\
100 & 51.9 & 5.9 & 10.1 & 12.3 \\
150 & 15.6 & 2.1 & 5.5 & 6.6 \\
200 & 0.0 & 0.0 & 1.7 & 2.3 \\
250 & & 0.0 & 0.0 \\
\hline
\end{tabular}

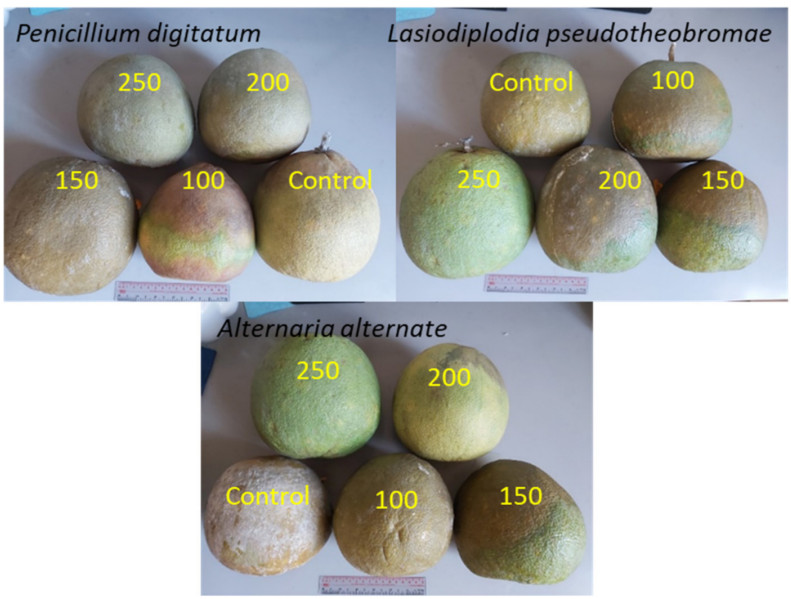

Figure 8. The antifungal activity of SCNs against three fungi on Citrus maxima after being treated for a week.

The antifungal activity of SCNs against P. digitatum, L. pseudotheobromae, and A. alternate caused the decay on Citrus reticulata $\times$ sinensis fruits as presented in Table 2 and Figure 9. Compared to that of the citrus maxima tests, the SCNs showed weaker antifungal activity against three fungi. It may be explained that citrus maxima fruits and their peels contain large numbers of bioactive compounds, such as vitamins, minerals, dietary fibers, pectins, and active phytochemicals, including phytophenolics (e.g., flavanones, flavones, flavonols, and phenolic acids) [36]. The infection and the lesion diameter were $25.6 \%$ and $3.1 \mathrm{~cm}$ (P. digitatum), $4.7 \mathrm{~cm}$ (L. pseudotheobromae), and $2.3 \mathrm{~cm}$ (A. alternate) after being treated with the SCN concentration at $200 \mathrm{ppm}$ for a week, while those of the control sample was 100\% and $9.5 \mathrm{~cm}$, respectively. It was not complete but the suppressed decay was still observed at the SCN concentration of 250 ppm for all fungi. The high antifungal activities of SCNs could be explained by the higher surface charge density (higher zeta potential), which provided them greater binding affinity for negatively charged fungal membrane [37].

Table 2. The antifungal activity of SCNs at different concentrations against three fungi on Citrus reticulata sinensis.

\begin{tabular}{ccccc}
\hline \multirow{2}{*}{$\begin{array}{c}\text { SCNs } \\
(\mathbf{p p m})\end{array}$} & $\begin{array}{c}\text { Infection } \\
(\mathbf{\%})\end{array}$ & \multicolumn{3}{c}{ Mean Lesion Diameter $(\mathbf{c m})$} \\
\cline { 3 - 5 } & 100 & P. digitatum & L. pseudotheobromae & A. alternate \\
\hline 0 & 100 & 9.5 & 9.5 & 9.5 \\
50 & 95.3 & 8.3 & 9.5 & 9.5 \\
100 & 61.9 & 4.9 & 9.3 & 9.1 \\
150 & 25.6 & 3.1 & 5.5 & 4.6 \\
200 & 0.7 & 0.5 & 4.7 & 2.3 \\
250 & & 1.0 & 0.6 \\
\hline
\end{tabular}




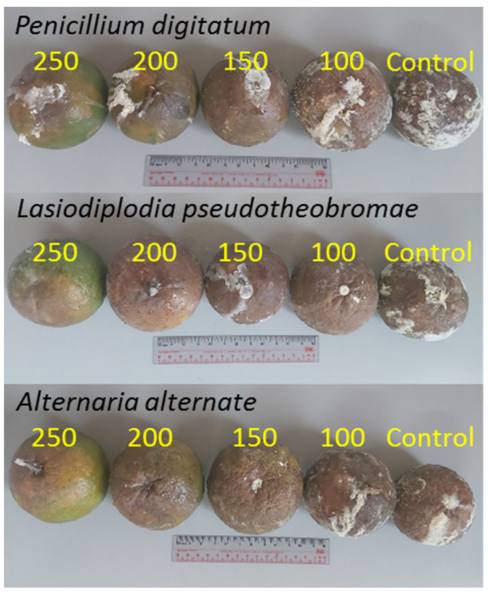

Figure 9. The antifungal activity of SCNs against three fungi on Citrus reticulata sinensis after being treated for a week.

Table 3 and Figure 10 show a high antifungal activity of the SCN against P. digitatum, L. pseudotheobromae, and A. alternate on Citrus reticulata Blanco. Similarly, the antifungal activity enhanced by increasing the $\mathrm{SCN}$ concentrations. By treating with an $\mathrm{SCN}$ concentration of $200 \mathrm{ppm}$ for a week, the mold infection and the lesion diameter were $15.5 \%$ and $1.1 \mathrm{~cm}$ (P. digitatum), $2.7 \mathrm{~cm}$ (L. pseudotheobromae), and $1.2 \mathrm{~cm}$ (A. alternate), respectively compared with those of the control samples of $100 \%$ and $6.5 \mathrm{~cm}$. When the SCN concentration was $250 \mathrm{ppm}$, the rot symptoms were not observed for all fungi, as shown in Figure 10. However, slight rot symptoms were observed in the sample incubated with the A. alternate suspension and treated with SCNs at $250 \mathrm{ppm}$. These findings are in agreement with those found in antifungal tests in vitro.

Table 3. The antifungal activity of SCNs at different concentrations against three fungi on Citrus reticulata Blanco.

\begin{tabular}{ccccc}
\hline \multirow{2}{*}{$\begin{array}{c}\text { SCNs } \\
(\mathbf{p p m})\end{array}$} & $\begin{array}{c}\text { Infection } \\
(\mathbf{\%})\end{array}$ & \multicolumn{3}{c}{ Mean Lesion Diameter $(\mathbf{c m})$} \\
\cline { 3 - 5 } & 100 & P. digitatum & L. pseudotheobromae & A. alternate \\
\hline 0 & 100 & 6.5 & 6.5 & 6.5 \\
50 & 65.3 & 5.3 & 6.5 & 6.3 \\
100 & 51.9 & 3.9 & 5.1 & 4.3 \\
150 & 15.5 & 1.1 & 3.5 & 3.6 \\
200 & 0.3 & 0.0 & 0.7 & 1.2 \\
250 & & & 0.0 & 0.6 \\
\hline
\end{tabular}

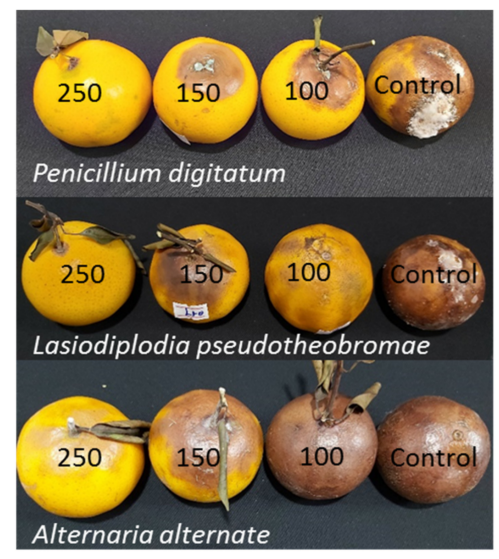

Figure 10. The antifungal activity of SCNs against three fungi on Citrus reticulata Blanco after being treated for a week. 


\section{Conclusions}

This study demonstrated the antifungal effectiveness of squid chitosan nanoparticles against Lasiodiplodia pseudotheobromae, Alternaria alternate, and Penicillium digitatum, which cause decay in the postharvest conservation of citrus fruits. SCNs exhibited a preservative capable of effectively controlling these common diseases in in vitro and in vivo tests as a biological fungicide. Practically, the samples treated with the SCN concentrations at 200 ppm (in vitro) and $250 \mathrm{ppm}$ (in vivo) showed the best control of mold growth and biomass that causes diseases in citrus fruits. The findings suggest that the SCN suspension is a potential candidate to reduce the spoilage rate of decomposition by various diseases, resulting in expanding the storage time and shelf life of citrus fruits to meet export requirements. However, the antifungal mechanism of the SCNs against Lasiodiplodia pseudotheobromae, Alternaria alternate, and Penicillium digitatum as well as the toxicity test of the treated fruits need further study.

Author Contributions: Conceptualization, N.V.H. (Nguyen Van Hoa) and H.N.C.; methodology, N.C.M.; formal analysis and investigation, H.N.C. and N.V.H. (Nguyen Van Hoa); writing-original draft preparation, H.N.C.; writing-review and editing, N.V.H. (Nguyen Van Hoa) and P.V.N.; project administration, D.H.G. and N.V.H. (Nguyen Van Hieu). All authors have read and agreed to the published version of the manuscript.

Funding: This research was funded by the Department of Science and Technology, Binh Phuoc province, Vietnam, under grant number 01/2019/KHCN.

Institutional Review Board Statement: Not applicable.

Informed Consent Statement: Not applicable.

Data Availability Statement: The data presented in this study are available in the article.

Conflicts of Interest: The authors declare no conflict of interest.

\section{References}

1. Tabti, L.; El Amine Dib, M.; Djabou, N.; Benyelles, N.G.; Paolini, J.; Costa, J.; Muselli, A. Control of fungal pathogens of Citrus sinensis L. by essential oil and hydrosol of Thymus capitatus L. J. Appl. Bot. Food Qual. 2014, 87, 279-285.

2. Tripathi, P.; Dubey, N.K. Exploitation of natural products as an alternative strategy to control postharvest fungal rotting of fruit and vegetables. Postharvest Biol. Technol. 2004, 32, 235-245. [CrossRef]

3. Porat, R.; Daus, A.; Weiss, B.; Cohen, L.; Fallik, E.; Droby, S. Reduction of postharvest decay in organic citrus fruit by a short hot water brushing treatment. Postharvest Biol. Technol. 2000, 18, 151-157. [CrossRef]

4. Chen, J.; Zhu, Z.; Fu, Y.; Cheng, J.; Xie, J.; Lin, Y. Identification of Lasiodiplodia pseudotheobromae causing fruit rot of Citrus in China. Plants 2021, 10, 202. [CrossRef] [PubMed]

5. Erasmus, A.; Lennox, C.L.; Korsten, L.; Lesar, K.; Fourie, P.H. Imazalil resistance in Penicillium digitatum and P. italicum causing citrus postharvest green and blue mould: Impact and options. Postharvest Biol. Technol. 2015, 107, 66-76. [CrossRef]

6. Costa, J.H.; Bazioli, J.M.; de Moraes Pontes, J.G.; Fill, T.P. Penicillium digitatum infection mechanisms in citrus: What do we know so far? Fungal Biol. 2019, 123, 584-593. [CrossRef]

7. Goosen, M.F. (Ed.) Applications of Chitan and Chitosan; CRC Press: Boca Raton, FL, USA, 1996

8. KaimBilla, R.E.; Islam, M.A.; Agunaou, M.; Soufiane, A. A promising chitosan/fluorapatite composite for efficient removal of lead (II) from an aqueous solution. Arab. J. Geosci. 2021, 14, 1134-1145. [CrossRef]

9. Pichyangkura, R.; Chadchawan, S. Biostimulant activity of chitosan in horticulture. Sci. Hortic. 2015, 196, 49-65. [CrossRef]

10. Baños, S.B.; López, M.H.; Molina, E.B. Growth inhibition of selected fungi by chitosan and plant extracts. Rev. Mex. Fitopatol. 2004, 22, 178-186.

11. Mohamed, M.D.; Moharam, M.H.; Ahmed, H.A. In vitro and in vivo toxicity of nano chitosan against Curvularia lunata, the causal microorganism of fruit rot and blight, a new disease of olive (O. europaea L.). Eur. J. Plant Pathol. 2021, 161, 881-894. [CrossRef]

12. Pabón-Baquero, D.; Velázquez-del Valle, M.G.; Evangelista-Lozano, S.; León-Rodriguez, R.; Hernández-Lauzardo, A.N. Chitosan effects on phytopathogenic fungi and seed germination of Jatropha curcas L. Rev. Chapingo Ser. Cienc. For. Ambiente 2015, 21, 241-253. [CrossRef]

13. Rodríguez, A.T.; Ramírez, M.A.; Cárdenas, R.M.; Hernández, A.N.; Velázquez, M.G.; Bautista, S. Induction of defense response of Oryza sativa L. against Pyricularia grisea (Cooke) Sacc. by treating seeds with chitosan and hydrolyzed chitosan. Pestic. Biochem. Phys. 2007, 89, 206-215. [CrossRef]

14. Yang, J.; Tian, F.; Wang, Z.; Wang, Q.; Zeng, Y.J.; Chen, S.Q. Effect of chitosan molecular weight and deacetylation degree on hemostasis. J. Biomed. Mater. Res. 2008, 84, 131-137. [CrossRef] 
15. Sathiyabama, M.; Parthasarathy, R. Biological preparation of chitosan nanoparticles and its in vitro antifungal efficacy against some phytopathogenic fungi. Carbohydr. Polym. 2016, 151, 321-325. [CrossRef]

16. Shukla, S.K.; Mishra, A.K.; Arotiba, O.A.; Mamba, B.B. Chitosan-based nanomaterials: A state-of-the-art review. Int. J. Biol. Macromol. 2013, 59, 46-58. [CrossRef]

17. Mohammed, S.R.; Zeitar, E.M.; Eskov, I.D. Inhibition of mycelial growth of Rhizoctonia solani by chitosan in vitro and in vivo. Open Agric. J. 2019, 13, 156-161. [CrossRef]

18. Cuevas-Acuña, D.A.; Plascencia-Jatomea, M.; Santacruz-Ortega, H.D.C.; Torres-Arreola, W.; Ezquerra-Brauer, J.M. Development of chitosan/squid skin gelatin hydrolysate films: Structural, physical, antioxidant, and antifungal properties. Coatings 2021, 11, 1088. [CrossRef]

19. Azhar, I.S.; Narisya, L. Antifungal power of chitosan extract from squid pen powder towards Candida albicans. Eur. Asian J. Biosci. 2020, 14, 3769-3772.

20. Xing, Y.; Wang, X.; Guo, X.; Yang, P.; Yu, J.; Shui, Y.; Chen, C.; Li, X.; Xu, Q.; Xu, L.; et al. Comparison of Antimicrobial Activity of Chitosan Nanoparticles against Bacteria and Fungi. Coatings 2021, 11, 769. [CrossRef]

21. Yien, L.; Zin, N.M.; Sarwar, A.; Katas, H. Antifungal activity of chitosan nanoparticles and correlation with their physical properties. Int. J. Biomater. 2012, 2012, 632698.

22. Orellano, M.S.; Isaac, P.; Breser, M.L.; Bohl, L.P.; Conesa, A.; Falcone, R.D.; Porporatto, C. Chitosan nanoparticles enhance the antibacterial activity of the native polymer against bovine mastitis pathogens. Carbohydr. Polym. 2019, 213, 1-9. [CrossRef]

23. Kritchenkov, A.S.; Zhaliazniak, N.V.; Egorov, A.R.; Lobanov, N.N.; Volkova, O.V.; Zabodalova, L.A.; Suchkova, E.P.; Kurliuk, A.V.; Shakola, T.V.; Rubanik, V.V., Jr.; et al. Chitosan derivatives and their based nanoparticles: Ultrasonic approach to the synthesis, antimicrobial and transfection properties. Carbohydr. Polym. 2020, 242, 116478. [CrossRef] [PubMed]

24. Abdallah, Y.; Liu, M.; Ogunyemi, S.O.; Ahmed, T.; Fouad, H.; Abdelazez, A.; Yan, C.; Yang, Y.; Chen, J.; Li, B. Bioinspired green synthesis of chitosan and zinc oxide nanoparticles with strong antibacterial activity against rice pathogen Xanthomonas oryzae pv. oryzae. Molecules 2020, 25, 4795. [CrossRef]

25. Bautista-Baños, S.; Hernandez-Lauzardo, A.N.; Velazquez-Del Valle, M.G.; Hernández-López, M.; Barka, E.A.; Bosquez-Molina, E.; Wilson, C.L. Chitosan as a potential natural compound to control pre and postharvest diseases of horticultural commodities. J. Crop Prot. 2006, 25, 108-118. [CrossRef]

26. Xu, H.; Ma, L.; Shi, H.; Gao, C.; Han, C. Chitosan-hyaluronic acid hybrid film as a novel wound dressing: In vitro and in vivo studies. Polym. Adv. Technol. 2007, 18, 869-875. [CrossRef]

27. Hernandez-Lauzardo, A.N.; Velázquez-del Valle, M.G.; Guerra-Sanchez, M.G. Current status of action mode and effect of chitosan against phytopathogens fungi. Afr. J. Microbiol. Res. 2011, 5, 4243-4247. [CrossRef]

28. Cuong, H.N.; Minh, N.C.; Hoa, N.V.; Trung, T.S. Preparation and characterization of high purity $\beta$-chitin from squid pens (Loligo chenisis). Int. J. Biol. Macromol. 2016, 93, 442-447. [CrossRef]

29. Hoa, N.V.; Vuong, N.T.H.; Minh, N.C.; Cuong, H.N.; Trung, T.S. Squid pen chitosan nanoparticles: Small size and high antibacterial activity. Polym. Bull. 2021, 78, 7313-7324.

30. Benbouazza, A.; Douira, A. First report of olive anthracnose, caused by Colletotrichum gloeosporioides, in Morocco. Atlas J. Biol. 2013, 2, 171-174.

31. Gomes, A.C.A.; da Costa Lima, M.; de Oliveira, K.Á.R.; dos Santos Lima, M.; Magnani, M.; Câmara, M.P.S.; de Souza, E.L. Coatings with chitosan and phenolic-rich extract from acerola (Malpighia emarginata DC) or jabuticaba (Plinia jaboticaba (Vell.) Berg) processing by-product to control rot caused by Lasiodiplodia spp. in papaya (Carica papaya L.) fruit. Int. J. Food Microb. 2020, 331, 108694. [CrossRef]

32. Meng, X.; Yang, L.; Kennedy, J.F.; Tian, S. Effects of chitosan and oligochitosan on growth of two fungal pathogens and physiological properties in pear fruit. Carbohydr. Polym. 2010, 81, 70-75. [CrossRef]

33. Waewthongrak, W.; Pisuchpen, S.; Leelasuphakul, W. Effect of Bacillus subtilis and chitosan applications on green mold (Penicilium digitatum Sacc.) decay in citrus fruit. Postharvest Biol. Technol. 2015, 99, 44-49. [CrossRef]

34. El Ghaouth, A.; Ponnampalam, R.; Castaigne, F.; Arul, J. Chitosan coating to extend the storage life of tomatoes. Hortic. Sci. 1992, 27, 1016-1018. [CrossRef]

35. Jiang, Y.; Li, Y. Effects of chitosan coating on postharvest life and quality of longan fruit. Food Chem. 2001, 73, 139-143. [CrossRef]

36. Liu, J.; Tian, S.; Meng, X.; Xu, Y. Effects of chitosan on control of postharvest diseases and physiological responses of tomato fruit. Postharvest Biol. Technol. 2007, 44, 300-306. [CrossRef]

37. Saharan, V.; Mehrotra, A.; Khatik, R.; Rawal, P.; Sharma, S.S.; Pal, A. Synthesis of chitosan based nanoparticles and their in vitro evaluation against phytopathogenic fungi. Int. J. Biol. Macromol. 2013, 62, 677-683. [CrossRef] 